\title{
Mild route to convert SiH compounds to their alkoxy analogues
}

\author{
Juraskova, Alena; A. Brook, Michael; Skov, Anne Ladegaard
}

Published in:

Industrial and Engineering Chemistry Research

Link to article, DOI:

10.1021/acs.iecr.0c03555

Publication date:

2020

Document Version

Peer reviewed version

Link back to DTU Orbit

Citation (APA):

Juraskova, A., A. Brook, M., \& Skov, A. L. (2020). Mild route to convert SiH compounds to their alkoxy analogues. Industrial and Engineering Chemistry Research, 59(41), 18412-18418.

https://doi.org/10.1021/acs.iecr.0c03555

\section{General rights}

Copyright and moral rights for the publications made accessible in the public portal are retained by the authors and/or other copyright owners and it is a condition of accessing publications that users recognise and abide by the legal requirements associated with these rights.

- Users may download and print one copy of any publication from the public portal for the purpose of private study or research.

- You may not further distribute the material or use it for any profit-making activity or commercial gain

- You may freely distribute the URL identifying the publication in the public portal

If you believe that this document breaches copyright please contact us providing details, and we will remove access to the work immediately and investigate your claim 


\section{Applied Chemistry}

\section{A Mild Route to Convert SiH Compounds to Their Alkoxy Analogues}

Alena Jurásková, Anne Ladegaard Skov, and Michael A. Brook

Ind. Eng. Chem. Res., Just Accepted Manuscript • DOI: 10.1021/acs.iecr.0c03555 • Publication Date (Web): 11 Sep 2020

Downloaded from pubs.acs.org on September 18, 2020

\section{Just Accepted}

"Just Accepted" manuscripts have been peer-reviewed and accepted for publication. They are posted online prior to technical editing, formatting for publication and author proofing. The American Chemical Society provides "Just Accepted" as a service to the research community to expedite the dissemination of scientific material as soon as possible after acceptance. "Just Accepted" manuscripts appear in full in PDF format accompanied by an HTML abstract. "Just Accepted" manuscripts have been fully peer reviewed, but should not be considered the official version of record. They are citable by the Digital Object Identifier (DOI®). "Just Accepted" is an optional service offered to authors. Therefore, the "Just Accepted" Web site may not include all articles that will be published in the journal. After a manuscript is technically edited and formatted, it will be removed from the "Just Accepted" Web site and published as an ASAP article. Note that technical editing may introduce minor changes to the manuscript text and/or graphics which could affect content, and all legal disclaimers and ethical guidelines that apply to the journal pertain. ACS cannot be held responsible for errors or consequences arising from the use of information contained in these "Just Accepted" manuscripts. 


\title{
A Mild Route to Convert SiH Compounds to Their
}

\author{
Alkoxy Analogues \\ Alena Jurásková,,$^{a, b}$ Anne Ladegaard Skov ${ }^{a}$ and Michael A. Brook ${ }^{b *}$ \\ a The Danish Polymer Centre, Department of Chemical and Biochemical Engineering, Technical \\ University of Denmark, Søltofts Plads, Building 227 Kgs. Lyngby DK - 2800 Denmark. \\ ${ }^{\mathrm{b}}$ Department of Chemistry and Chemical Biology, McMaster University, 1280 Main St. W., \\ Hamilton ON Canada L8S 4M1.
}

\begin{abstract}
Alkoxysilanes, particularly ethoxysilanes, are widely used crosslinkers for the moisture induced, room temperature vulcanization of silicones. Karstedt's platinum catalyst is shown to be effective at converting commercially available small hydrosiloxanes containing 1-8 SiH groups, and higher molecular weight telechelic and pendant hydrosiloxane polymers, into the corresponding alkoxycompounds. Kinetic studies demonstrated that relatively high concentrations of platinum -500 ppm - were required for practical reaction rates to be realized. As with other silyl ether forming processes, steric hindrance at both carbon (alcohol) and silicon center retard reaction progress. This alternative use of the platinum catalyst, employed widely in the silicone industry, permits
\end{abstract}


ready formation of small molecule and polymeric RTV alkoxysiloxane crosslinkers that can be used to tailor network structures.

\section{Introduction}

Moisture cure room temperature vulcanization - RTV (note: some platinum-catalyzed hydrosilylation processes are also labelled RTV) constitutes an important cure technology that is used in a variety of applications from silicone caulking, that will be familiar to consumers, to commercial assembly of structural glazing. ${ }^{1}$ The mechanism of tin-catalyzed moisture cure is not completely understood, but the seminal paper by van der Weij clarifies the roles of water, tin, silanol and functional silane crosslinker. ${ }^{2}$ The rates of cure are controlled by the concentrations of the various constituents and by the leaving group abilities of the functional groups. The relative reactivities of industrial crosslinkers follow the order SiOCOR (acetate or other carboxylates) $>$ Si-oxime (typically derived from acetone) $>\mathrm{SiOR}($ normally $\mathrm{R}=\mathrm{Me}, \mathrm{Et}){ }^{3}$

One problem with RTV cure is associated with controlling the rate of cure so that elastomer formation is sufficiently rapid during application (e.g., skinover in 5 minutes, complete cure in 24 hours), but precured materials have an acceptable pot life. Alkoxysilanes are preferred as crosslinkers for the latter reason. ${ }^{4}$ To speed up cure, for example in glazing applications, an RTV-2 process (two components that are mixed during application) is used, with water provided in one of the components. RTV-1 processes - a single component - utilize moisture from the atmosphere to control cure rate and, in general, acetoxy- or oxime-modified silanes as crosslinkers. In both cases, reaction rates slow dramatically with substitution: $\mathrm{Si}(\mathrm{OR})_{4}>(\operatorname{SiliconeO}) \mathrm{Si}(\mathrm{OR})_{3}>$ $(\text { SiliconeO })_{2} \mathrm{Si}(\mathrm{OR})_{2}>>(\text { SiliconeO })_{3} \mathrm{Si}(\mathrm{OR}) .^{3}$ 
A relatively small library of alkoxy-compounds are normally used in commercial RTV processes, primarily, $\mathrm{Si}(\mathrm{OR})_{4}$ and $\mathrm{MeSi}(\mathrm{OR})_{3}, \mathrm{R}=\mathrm{Me}$, Et. Note that some commercial adhesives have polymers terminated with $\operatorname{MeSi}(\mathrm{OR})_{2}$-silicone groups, which constitutes a related class of compounds. ${ }^{4}$ It is clear that better elastomeric products arise from better control of structures, including overall network structures. ${ }^{5,6}$ There is therefore an incentive to develop new alkoxyfunctional crosslinkers that could be used to control both rates of cure and final network properties. There are many synthetic routes leading to alkoxysilanes. A very common process, because of the availability of starting materials, uses simple alcoholysis of the chlorosilanes produced in the Direct Process. While this is a facile process for simple silane monomers, it is not very convenient when more complicated structures containing Si-O-Si linkages are also present, as these undergo a variety of concomitant reactions in the presence of the $\mathrm{HCl}$ byproduct; base-catalyzed alcoholysis is equally compromised. That is, any residual catalyst can facilitate the depolymerization of silicone polymers present. ${ }^{3}$

Another route for the preparation of alkoxysilanes utilizes hydrosilanes, which also undergo alcoholysis under mild conditions: Note the reaction occurs with concomitant formation of hydrogen gas, which is a safety issue due both to the flammability of hydrogen and the potential for increases in pressure. Normally, these processes are catalyzed by base ${ }^{7}$ or a variety of metals, including Ir, Ru, Rh, Sn, etc., as described in excellent reviews. ${ }^{8,}{ }^{9}$ Karstedt's platinum catalyst is the workhorse in the silicone industry for hydrosilylation cure of elastomers, ${ }^{10}$ and has been shown to catalyze alcoholysis of small silanes. ${ }^{11,} 12$ The group of Marciniec, preeminent experts on transition metal hydrosilylation, ${ }^{13}$ has recently examined the utilization of selected $\mathrm{Pd}$ and $\mathrm{Pt}$ catalysts in the oxidation of silsesquioxanes compounds with attached Si-H moieties. ${ }^{14}$ Note that 
the related hydrolysis of $\mathrm{SiH}$ groups $(\mathrm{SiH} \rightarrow \mathrm{SiOH})$ can also be catalyzed by a variety of transition metals. ${ }^{15,16}$

We report the use of Karstedt's catalyst to prepare alkoxysiloxanes, including polymeric structures, as RTV crosslinkers and chain extenders. The process is mild, facile and occurs at moderate rates, which facilitates the handling of the hydrogen gas by-product. We examine the viability and optimize reaction conditions of the process for different alcohols and, more importantly, different alkoxysiloxane structural motifs.

\section{Experimental Section}

\section{Materials}

Hydride-terminated polydimethylsiloxanes- $-\mathrm{HMe}_{2} \mathrm{Si}\left(\mathrm{OSiMe}_{2}\right)_{\mathrm{n}} \mathrm{OSiMe}{ }_{2} \mathrm{H} ; \mathbf{H}-\mathbf{D}_{\mathbf{8}}-\mathbf{H} \mathrm{n}=8, \mathrm{M}_{\mathrm{n}}=$ $728 \mathrm{~g} \mathrm{~mol}^{-1}$, DMS-H03; H-D 15 -H $\mathrm{n}=15, \mathrm{M}_{\mathrm{n}}=1250 \mathrm{~g} \mathrm{~mol}^{-1}$ DMS-H11; and H-D $\mathbf{1 4 5}-\mathbf{H} \mathrm{n}=145$, $\mathrm{M}_{\mathrm{n}}=10890 \mathrm{~g} \mathrm{~mol}^{-1}$ DMS-H25) measured in all cases by end group analysis using ${ }^{1} \mathrm{H}$ NMR, methylhydrosiloxane-dimethylsiloxane trimethylsiloxane-terminated copolymers$\left(\mathrm{Me}_{3} \mathrm{SiO}(\mathrm{HMeSiO})_{\mathrm{m}}\left(\mathrm{Me}_{2} \mathrm{SiO}\right)_{\mathrm{n}}-\mathrm{SiMe}_{3}, \mathbf{D}^{\mathrm{H}}{ }_{8} \mathbf{D}_{7} \mathrm{~m} \sim 8, \mathrm{n} \sim 7, \mathrm{MW}=900-1200 \mathrm{~g} / \mathrm{mol}, \mathrm{HMS}-501 ;\right.$ $\mathbf{D}_{8}{ }_{8} \mathbf{D}_{72} \mathrm{~m} \sim 8, \mathrm{n} \sim 72, \mathrm{MW}=5500-6500 \mathrm{~g} / \mathrm{mol}, \mathrm{HMS}-082 ;$ and $\mathbf{D}^{\mathbf{H}}{ }_{5} \mathbf{D}_{\mathbf{2 0}} \mathrm{m} \sim 5, \mathrm{n} \sim 20, \mathrm{MW}=$ $1900-2000 \mathrm{~g} / \mathrm{mol}, \quad \mathrm{HMS}-151, \quad$ octakis(dimethylsiloxy)-T8-silsesquioxane $\left(\left(\mathrm{QM}^{\mathrm{H}}\right)_{8}\right)$, tetrakis(dimethylsiloxy)silane $\quad\left(\left(\mathrm{HMe}_{2} \mathrm{SiO}\right)_{4} \mathrm{Si}\right) \quad\left(\mathrm{Q}\left(\mathrm{M}^{\mathrm{H}}\right)_{4}\right)$, methyltris-(dimethylsiloxy)silane $\left(\left(\mathrm{HMe}_{2} \mathrm{SiO}\right)_{3} \mathrm{SiMe}\right), \quad$ phenyltris(dimethylsiloxy)silane $\quad\left(\left(\mathrm{HMe}_{2} \mathrm{SiO}\right)_{3} \mathrm{SiPh}\right), \quad$ and pentamethyldisiloxane $\left(\mathrm{HMe}_{2} \mathrm{SiOSiMe}_{3}\right)$ were purchased from Gelest. Platinum(0)-1,3-divinyl1,1,3,3-tetramethyldisiloxane complex solution (Karstedt's catalyst, $\mathrm{Pt} \sim 2 \%$, in xylene) and anhydrous alcohols (methanol (MeOH), ethanol (EtOH), n-butyl alcohol (n-BuOH), 2-propanol (IPA), $t$-butyl alcohol ( $t$-BuOH), and benzyl alcohol $\left.\left(\mathrm{PhCH}_{2} \mathrm{OH}\right)\right)$ were obtained from Sigma 
Aldrich. Chromium(III) acetylacetonate was purchased from Sigma-Aldrich. All alcohols were dried over molecular sieves before use. Toluene and dichloromethane (Caledon) were dried over a column of activated alumina. Activated carbon, granular, 4-14 mesh was supplied by Aldrich Chemical Company, Inc. Celite ${ }^{\circledR} 545$ was purchased from Millipore Sigma.

\begin{abstract}
Methods
Nuclear magnetic resonance ( ${ }^{1} \mathrm{H}$ NMR, $500 \mathrm{MHz}$; ${ }^{29} \mathrm{Si} \mathrm{NMR}$, $\left.99.4 \mathrm{MHz}\right)$ characterization was performed on a Bruker AV $500 \mathrm{MHz}$ spectrometer at room temperature using deuterated solvents chloroform- $d$ or toluene- $d_{8}$. A small amount of chromium(III) acetylacetonate was added to sample as a relaxation agent for the ${ }^{29} \mathrm{Si}$ NMR spectra. When NMR used to follow the kinetics of reactions of Si-H with alcohols, all the reagents were placed in the NMR tube and mixed but, before placing the tube into the Bruker AV $500 \mathrm{MHz}$ spectrometer auto sampler, the normal NMR cap was exchanged for one with a small hole to reduce any pressure created by adventitious $\mathrm{H}_{2}$ development.
\end{abstract}

Mass spectroscopy (MS) was performed using electrospray ionization mass spectrometry (ESIMS) on an Agilent 6340 Ion Trap mass spectrometer; ammonia or $\mathrm{NH}_{4} \mathrm{OAc}$ was added for analysis.

\title{
Kinetic study of the Alcoholysis of Si-H Compounds
}

Reactions were performed directly in NMR tube at room temperature. ${ }^{1} \mathrm{H}$ NMR spectra were collected during the reaction at different time points. The reaction rates were calculated by following the loss of the $\mathrm{Si}-\mathrm{H}$ signal and growth of a $\mathrm{Si}-\mathrm{O}-\mathrm{CH}_{2}$ - signal that, in most cases, was quite distinct from the free alcohol (Figure 1). 


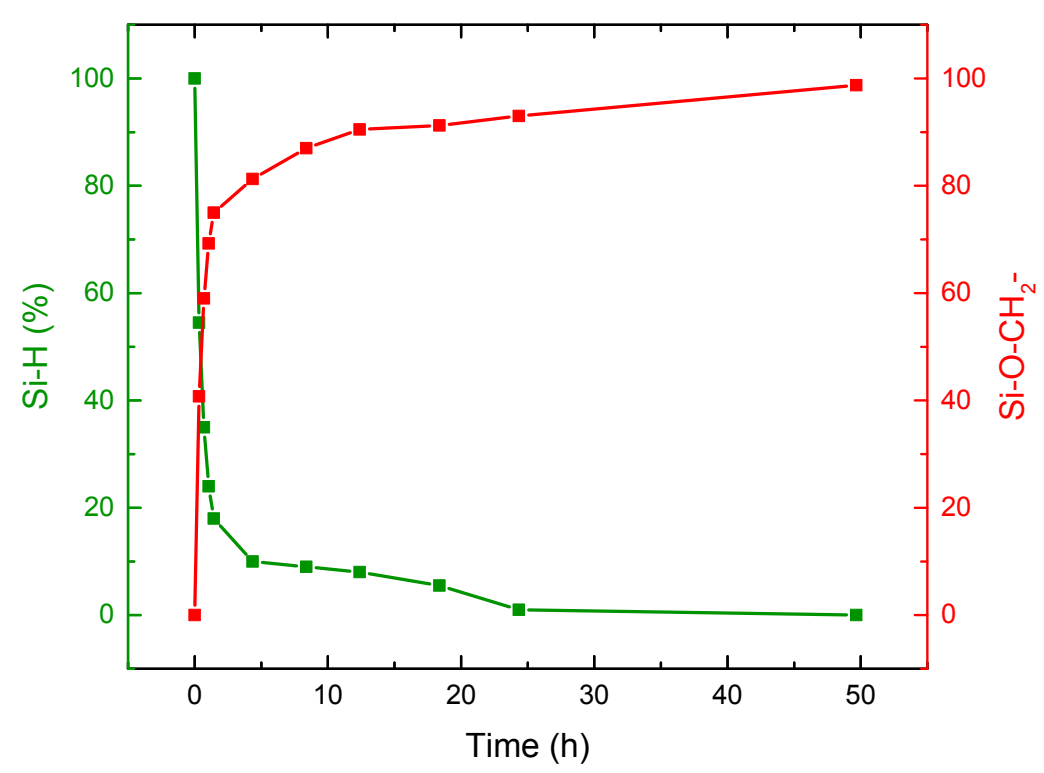

Figure 1 Rates of ethanolysis of $\mathbf{H}-\mathbf{D}_{\mathbf{8}} \mathbf{- H}$ in presence of $500 \mathrm{ppm}$ of Karstedt's catalyst (model reaction). The loss of the $\mathrm{Si}-\mathrm{H}(\%)$ and the growth of the $\mathrm{Si}-\mathrm{O}-\mathrm{CH}_{2^{-}}(\%)$ were calculated by following the corresponding ${ }^{1} \mathrm{H}$ NMR spectra signals over the reaction time (Supporting Information).

\section{Optimizing the quantity of Karstedt's catalyst}

Five identical solutions consisting of $\mathbf{H}-\mathbf{D}_{\mathbf{8}}-\mathbf{H}(20 \mathrm{mg}, 0.054 \mathrm{mmol}), 5$ eq. of ethanol $(15.7 \mu \mathrm{L}$, $0.269 \mathrm{mmol})$, and toluene- $d_{8}(0.7 \mathrm{~mL})$ were prepared in Eppendorf tubes and subsequently transferred into NMR tubes to collect initial ${ }^{1} \mathrm{H}$ NMR spectra. After the initial spectra were recorded, 50, 250, 500, 750, and $1000 \mathrm{ppm}$ of Pt, respectively (Table 1), was pipetted separately into the 5 NMR tubes and quickly mixed with the rest of the solution by shaking the closed NMR tube. At 750 and $1000 \mathrm{ppm}$ of $\mathrm{Pt}$, it was possible to observe evolution of $\mathrm{H}_{2}$ bubbles. Note: ppm refers to the mass of $\mathrm{Pt} /$ mass of hydrosiloxane $\mathrm{x} 10^{6} .{ }^{1} \mathrm{H}$ NMR spectra were run at given time intervals. See Figure 2. 
Table 1. Amounts of Karstedt's catalyst added into the solutions.

\begin{tabular}{|c|c|c|c|c|c|}
\hline \multicolumn{5}{|c|}{ Karstedt's catalyst } \\
\hline \multirow{2}{*}{$\mu \mathrm{Lt}(\mathrm{ppm})^{\mathrm{a}}$} & 50 & 250 & 500 & 750 & 1000 \\
\hline & \multicolumn{2}{|c|}{$0.05 \mathrm{wt} \%$ solution in toluene } & \multicolumn{3}{|c|}{$0.1 \mathrm{wt} \%$ solution in toluene } \\
\cline { 2 - 6 } & 1.17 & 5.85 & 5.85 & 8.77 & 11.70 \\
\hline
\end{tabular}

${ }^{a} \mathrm{ppm}$ is calculated in mass of $\mathrm{Pt} /$ mass of hydrosiloxane $\mathrm{x} 10^{6}$.

\section{Efficiency of reaction of simple alcohols: General procedure shown for ethanol (model reaction)}

A solution consisting of $\mathbf{H}_{-} \mathbf{D}_{\mathbf{8}}-\mathbf{H}(20 \mathrm{mg}, 0.054 \mathrm{mmol}), 5$ eq. of ethanol $(15.7 \mu \mathrm{L}, 0.269 \mathrm{mmol})$, and $0.7 \mathrm{~mL}$ of toluene- $d_{8}$ was prepared in an Eppendorf tube and subsequently transferred into an NMR tube to collect the initial spectra. After the initial ${ }^{1} \mathrm{H}$ NMR spectrum was run, Karstedt's catalyst (500 ppm of Pt, $5.85 \mu \mathrm{L}$ of a $0.1 \mathrm{wt} \%$ solution in toluene) was pipetted into the NMR tubes and quickly mixed with the rest of the solution by shaking the closed NMR tube. ${ }^{1} \mathrm{H}$ NMR spectra were run at given time intervals.

The same procedure was repeated with methanol (10.89 $\mu \mathrm{L}, 0.269 \mathrm{mmol})$, butanol $(24.61 \mu \mathrm{L}$, $0.269 \mathrm{mmol})$, IPA $(20.48 \mu \mathrm{L}, 0.269 \mathrm{mmol}), t$-BuOH $(25.71 \mu \mathrm{L}, 0.269 \mathrm{mmol})$, benzyl alcohol (23.64 $\mu \mathrm{L}, 0.269 \mathrm{mmol})$. The toluene- $d_{8}$ was added to reach total solvent volume $715.70 \mu \mathrm{L}$, which was the solvent volume of the reaction above, considered as the model reaction. See Figure 3.

Ethanolysis of $\mathrm{HMe}_{2} \mathrm{SiOSiMe}_{3},\left(\mathrm{HMe}_{2} \mathrm{SiO}\right)_{3} \mathrm{SiMe},\left(\mathrm{HMe}_{2} \mathrm{SiO}\right)_{3} \mathrm{SiPh}, \mathrm{Q}\left(\mathrm{M}^{\mathrm{H}}\right)_{4}$ and $\left(\mathrm{QM}^{\mathrm{H}}\right)_{8}$

The general method was used: $\mathbf{H M e}_{2} \mathrm{SiOSiMe}_{3}(20 \mathrm{mg}, 0.135 \mathrm{mmol}), 5$ eq of ethanol (39.36 $\mu \mathrm{L}, 0.674 \mathrm{mmol}$ ), toluene- $d_{8}$ (added to reach total solvent volume $715.7 \mu \mathrm{L}$ ), and Karstedt's catalyst (500 ppm of Pt, $5.85 \mu \mathrm{L}$ of a $0.1 \mathrm{wt} \%$ solution in toluene). ${ }^{1} \mathrm{H}$ NMR spectra were run at given time intervals. 
(HMe $\left._{2} \mathbf{S i O}\right)_{3} \mathbf{S i M e}(20 \mathrm{mg}, 0.223 \mathrm{mmol}), \mathrm{EtOH}(65.21 \mu \mathrm{L}, 1.117 \mathrm{mmol})$; ( $\left.\mathbf{H M e}_{2} \mathbf{S i O}\right)_{3} \mathbf{S i P h}(20$ mg, $0.181 \mathrm{mmol}), \operatorname{EtOH}(52.97 \mu \mathrm{L}, 0.907) ; \mathbf{Q}\left(\mathbf{M}^{\mathbf{H}}\right)_{4}(20 \mathrm{mg}, 0.243 \mathrm{mmol}), \mathrm{EtOH}(71.05 \mu \mathrm{L}, 1.217$ mmol); $\left(\mathbf{Q M}^{\mathbf{H}}\right)_{\mathbf{8}}(20 \mathrm{mg}, 0.157 \mathrm{mmol})$. See Figure 4.

\section{Ethanolysis of $H-D_{8}-H, H-D_{15}-H, H-D_{145}-H, D_{8}^{H_{8}} D_{7}, D^{H_{8}} D_{72}$, and $D^{H_{5}} D_{20}$}

The general method was used: $\mathbf{H}_{-}-\mathbf{D}_{\mathbf{8}} \mathbf{- H}(20 \mathrm{mg}, 0.054 \mathrm{mmol}), 5$ eq. of ethanol $(15.7 \mu \mathrm{L}, 0.269$ mmol), toluene- $d_{8}$ (added to reach total solvent volume $715.70 \mu \mathrm{L}$ ), and Karstedt's catalyst $(500$ ppm of $\mathrm{Pt}, 5.85 \mu \mathrm{L}$ of a $0.1 \mathrm{wt} \%$ solution in toluene). ${ }^{1} \mathrm{H}$ NMR spectra were run at given time intervals.

$\mathbf{H}_{\mathbf{1 5}} \mathbf{- H}(20 \mathrm{mg}, 0.032 \mathrm{mmol}), \mathrm{EtOH}(9.26 \mu \mathrm{L}, 0.159 \mathrm{mmol}) . \mathbf{H}-\mathbf{D}_{\mathbf{1 4 5}}-\mathbf{H}(20 \mathrm{mg}, 0.003 \mathrm{mmol})$,

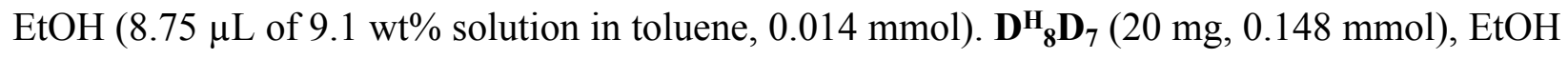
(43.10 $\mu \mathrm{L}, 0.738 \mathrm{mmol}) . \mathbf{D}^{\mathbf{H}} \mathbf{D}_{\mathbf{7}}(20 \mathrm{mg}, 0.026 \mathrm{mmol}), \mathrm{EtOH}(7.56 \mu \mathrm{L}, 0.129 \mathrm{mmol}) ; \mathbf{D}^{\mathbf{H}}{ }_{\mathbf{5}} \mathbf{D}_{\mathbf{2 0}}(20$ mg, $0.052 \mathrm{mmol})$, EtOH (15.134 $\mu \mathrm{L}, 0.259 \mathrm{mmol})$. See Figure 4.

\section{Larger Scale Synthesis: General procedure shown for $\left(\mathrm{QM}^{0 \mathrm{Et}}\right)_{8}$}

$\left(\mathrm{QM}^{\mathrm{H}}\right)_{8}(3 \mathrm{~g}, 23.576 \mathrm{mmol})$ was placed in a $50 \mathrm{~mL}$ round-bottomed flask and dissolved in $30 \mathrm{~mL}$ of dry toluene. After the $\left(\mathrm{QM}^{\mathrm{H}}\right)_{8}$ had dissolved, 5 eq. of ethanol $(6.88 \mathrm{~mL}, 117.881 \mathrm{mmol})$ was added followed by addition of Karstedt's catalyst (1000 ppm of Pt, $175.44 \mu \mathrm{L})$. The reaction was allowed to run overnight at room temperature under a nitrogen blanket. Complete conversion of $\mathrm{Si}-\mathrm{H}$ group to the Si-OEt was determined by ${ }^{1} \mathrm{H}$ NMR. Karstedt's catalyst was removed by stirring the reaction solution over activated carbon. The product was collected by filtration through Celite and evaporation of the solvents on rotary evaporator.

$\left(\mathrm{QM}^{\mathrm{OEt}}\right)_{8}:{ }^{1} \mathrm{H} \mathrm{NMR}(600 \mathrm{MHz}$, chloroform- $d): \delta 3.77\left(\mathrm{q}, 15.04 \mathrm{H}, \mathrm{J}=7 \mathrm{~Hz}, \mathrm{OCH}_{2} \mathrm{CH}_{3}\right), 1.21(\mathrm{t}$, 24.2H, $\left.J=7 \mathrm{~Hz}, \mathrm{OCH}_{2} \mathrm{CH}_{3}\right), 0.15\left(\mathrm{~s}, 48 \mathrm{H}, \mathrm{SiMe}_{2}\right),{ }^{29} \mathrm{Si} \mathrm{NMR}(99.4 \mathrm{MHz}$, chloroform- $d): \delta$-9.89 (q, 8.24 Si, $\left.\left.\mathrm{Si}(\mathrm{Me})_{2}\right) \mathrm{OCH}_{2} \mathrm{CH}_{3}\right), \delta-110.04$ (s, $8 \mathrm{Si}, 110.04$ (s, $8 \mathrm{Si}, \mathrm{SiO}_{4 / 2}$ ). High Res MS calc. for $\left[\mathrm{C}_{32} \mathrm{H}_{88} \mathrm{O}_{28} \mathrm{Si}_{16}+\mathrm{NH}_{4}\right]^{+}$1388.2109, found 1388.2085. Reaction yield 96\%. 
EtO-D -OEt: $\mathrm{H}_{\mathbf{8}} \mathrm{D}_{8}$-H (3 g, $\left.8.065 \mathrm{mmol}\right)$, dry toluene $(5 \mathrm{~mL})$, EtOH (5 eq., $2.35 \mathrm{~mL}, 40.323$ mmol), and Karstedt's catalyst (300 ppm of Pt, $52.63 \mu \mathrm{L})$.

${ }^{1} \mathrm{H}$ NMR (600 MHz, chloroform- $d$ ): $\delta 3.67$ (q, 4H, $\left.\mathrm{OCH}_{2} \mathrm{CH}_{3}, J=7 \mathrm{~Hz}\right), \delta 1.14(\mathrm{t}, 6.17 \mathrm{H}, J=7$ $\left.\mathrm{Hz}, \mathrm{OCH}_{2} \mathrm{CH}_{3}\right), \delta 0.13-0.10(\mathrm{~m}, 62.23 \mathrm{H}, \mathrm{SiMe})$. Reaction yield $85 \%$.

(EtOMe $2 \mathrm{SiO})_{3} \mathrm{SiMe}:\left(\mathrm{HMe}_{2} \mathrm{SiO}\right)_{3} \mathrm{SiMe}(0.5 \mathrm{~g}, 580.59 \mu \mathrm{L}, 5.584 \mathrm{mmol})$, dichloromethane (1 mL), EtOH (5eq., $1.63 \mathrm{~mL}, 27.922 \mathrm{mmol}$ ), and Karstedt's catalyst (500 ppm of Pt, $14.62 \mu \mathrm{L}$ ). Dichloromethane was used as lower boiling point solvent to reduce product losses during the solvent evaporation. Reaction yield 44\% (due to starting material volatility).

${ }^{1} \mathrm{H}$ NMR (600 MHz, chloroform- $d$ ): $\delta 3.84$ - $3.69\left(\mathrm{~m}, 4.21 \mathrm{H}, \mathrm{OCH}_{2} \mathrm{CH}_{3}\right), \delta 1.25-1.2(\mathrm{~m}, 6.28 \mathrm{H}$, $\left.\mathrm{OCH}_{2} \mathrm{CH}_{3}\right), \delta 0.23-0.08(\mathrm{~m}, 21 \mathrm{H}, \mathrm{SiMe}+\mathrm{SiMe} 2)$. calc. for $\left[\mathrm{C}_{13} \mathrm{H}_{36} \mathrm{O}_{6} \mathrm{Si}_{4}+\mathrm{NH}_{4}\right]^{+} 418.1927$, found 418.1930 .

\section{Results}

\section{Alcoholysis of a telechelic linear silicone polymer}

Initial experiments focused on optimizing reaction conditions for alcoholysis of a model telechelic silicone polymer $\mathbf{H}-\mathbf{D}_{\mathbf{8}}-\mathbf{H}$. The optimization reactions were conducted in NMR tubes with spectra taken at different time points. The reaction rates were calculated by following the loss of Si-H and the growth of Si-O-CH${ }_{2}$ - signals from the EtO-D - -OEt formed (Figure S1).

Quantities of Karstedt's catalyst ranging from 50 ppm to 1000 ppm were investigated. From the graph in Figure 2 it can be seen that the loss of the $\mathrm{Si}-\mathrm{H}$ groups matches the growth of the Si-O$\mathrm{CH}_{2} \mathrm{CH}_{3}$ groups. This correlation signifies that no significant side reactions such as hydrolysis or condensation were occurring in the tested range of catalyst concentrations. A concentration of 500 ppm was subsequently chosen to facilitate alcoholysis of the model hydrosiloxane (H-D $\mathbf{-}-\mathbf{H})$ at 
room temperature, as it balances the need for a relatively rapid reaction rate with the quantity of expensive platinum catalyst required. These are much higher platinum catalyst concentrations compared to the quantity used for hydrosilylation of alkenes. As a result of Pt colloid formation during the reaction, ${ }^{17}$ the reaction solutions turn yellow to brown at the end of reaction. In addition, at the 750 and $1000 \mathrm{ppm}$ level of catalyst, it was possible to directly observe the evolution of $\mathrm{H}_{2}$ gas.
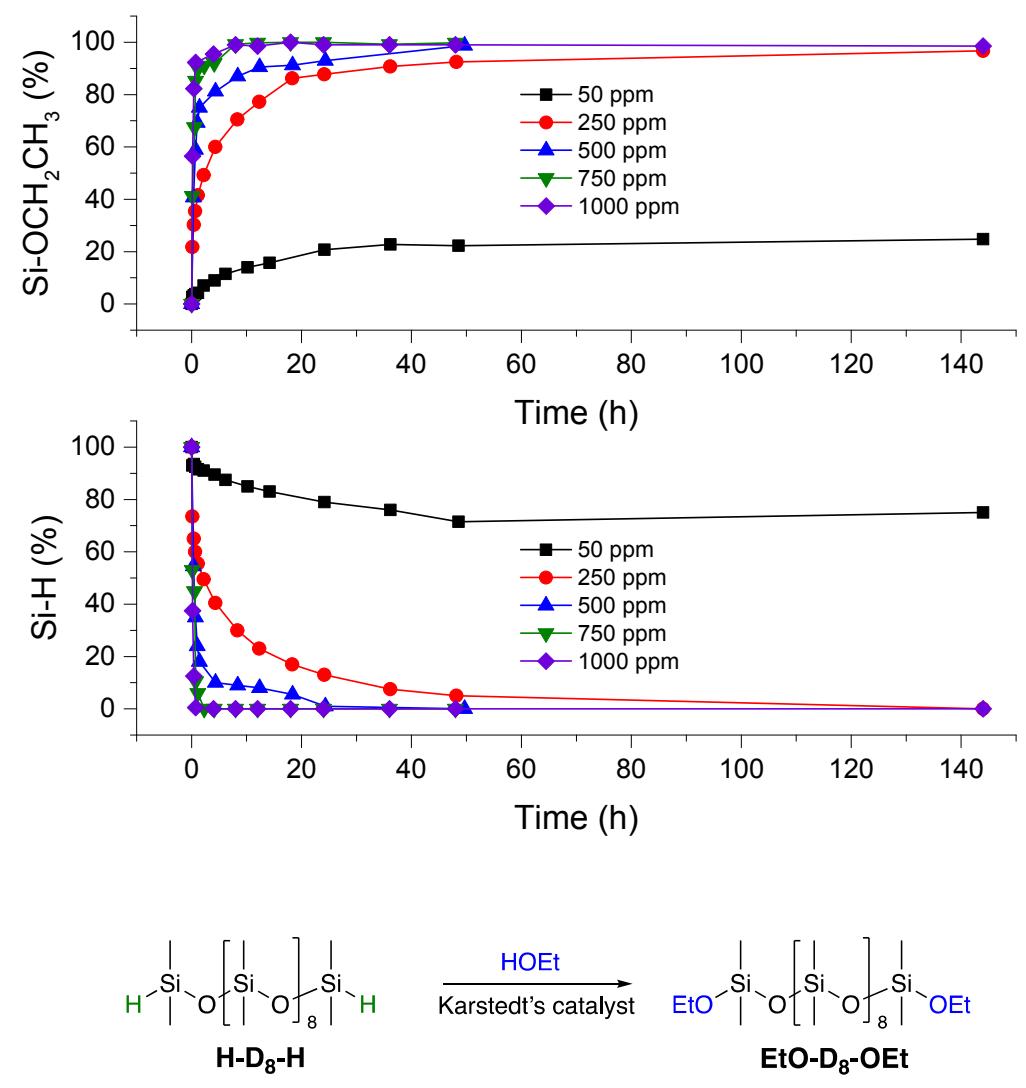

Figure 2. Loss of Si-H group (\%) and growth of $\mathrm{Si}-\mathrm{OCH}_{2} \mathrm{CH}_{3}$ group (\%) concentration during the ethanolysis of $\mathbf{H}-\mathbf{D}_{\mathbf{8}}-\mathbf{H}$ using different quantities of Karstedt's catalyst.

The efficiency of alcoholysis of $\mathbf{H}-\mathbf{D}_{\mathbf{8}}-\mathbf{H}$ with different alcohols was tested using a Karstedt's catalyst concentration of $500 \mathrm{ppm}$. In all cases, except $t$-BuOH and benzyl alcohol, the Si-O- $\mathrm{CH}_{2^{-}}$ 
signal was quite distinct from that of the free alcohol $\mathrm{HO}-\mathrm{CH}_{2^{-}}$. As before, the direct relation between loss of $\mathrm{Si}-\mathrm{H}$ and growth of $\mathrm{Si}-\mathrm{O}-\mathrm{CH}_{2}$ - signals showed that no side reactions are occurring (Figure 3). As expected, ${ }^{18,19}$ the efficiency of the alcoholysis reaction dropped with increased steric bulk at the alcohol, with the exception of methanol, following the order shown in Figure 3. The small differences in rates of $\mathrm{EtOH}$ and $n-\mathrm{BuOH}$ are inferred to be within experimental error.
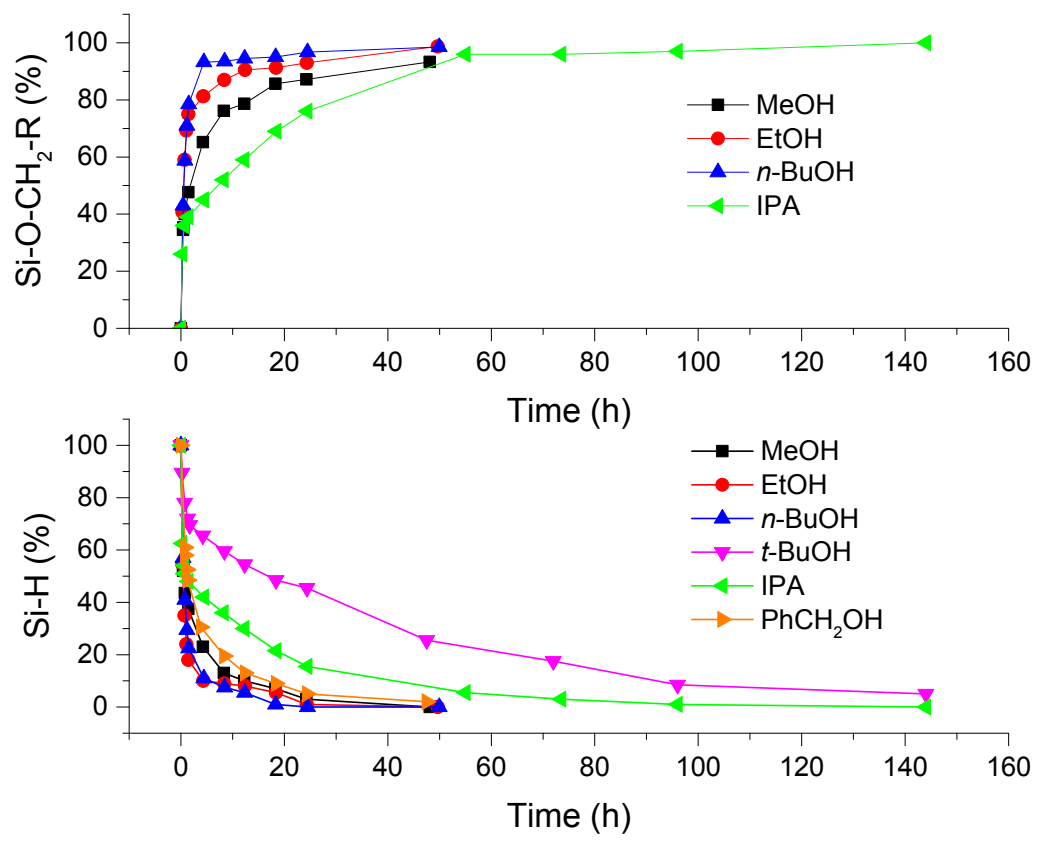

EtOH $\sim n-\mathrm{BuOH} \geq \mathrm{MeOH}>\mathrm{PhCH}_{2} \mathrm{OH}>\mathrm{IPA}>t$ - $>\mathrm{BuH}$<smiles>CCCCOCc1ccccc1CO</smiles>

Figure 3. Loss of $\mathrm{Si}-\mathrm{H}$ group (\%) and growth of $\mathrm{Si}-\mathrm{O}-\mathrm{CH}_{2}-\mathrm{R}$ group (\%) during the alcoholysis of H-D $\mathbf{8}-\mathbf{H}$ using 500 ppm of Karstedt's catalyst (top). The order of alcohol efficiency (bottom).

\section{Ethanolysis of hydrosiloxanes}

The relative reactivities of a variety of siloxanes structural motifs to alcoholysis was studied (Figure 4). In all cases, ethanol was chosen as the alcohol, as ethoxysilanes are the most widely 
used reagents for RTV moisture cure silicone elastomers. ${ }^{3}$ The studied compounds included telechelic and pendant SiH-containing polymers, monofunctional capping agents and tri-, tetraand octa-functional crosslinkers. The reactions were performed in NMR tubes with ethanol and 500 ppm of Pt. In most cases, the Si-O- $\mathrm{CH}_{2}$ - signal was quite distinct from the free alcohol, which allowed simultaneous tracking of both moieties (Figure 4).

A

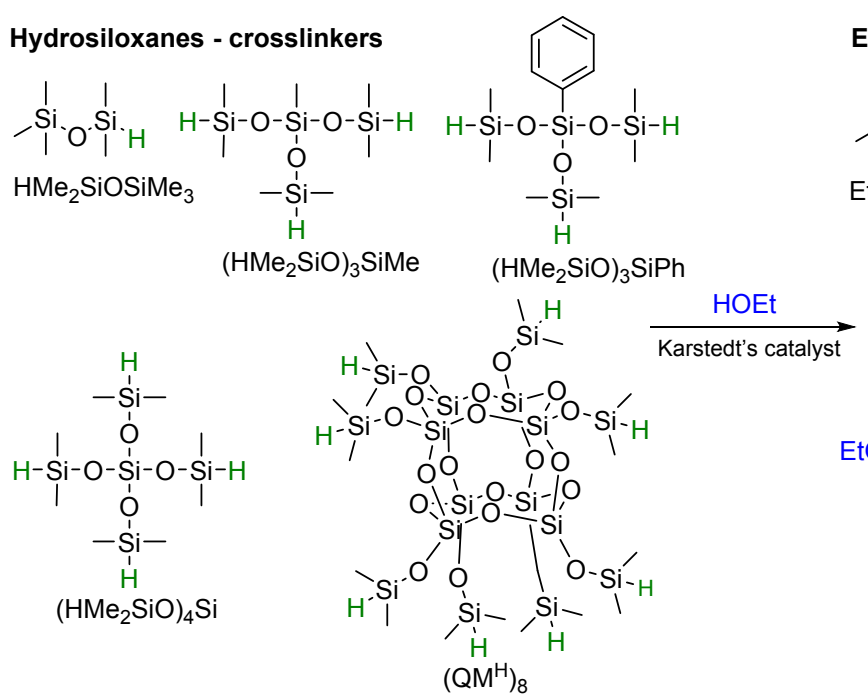

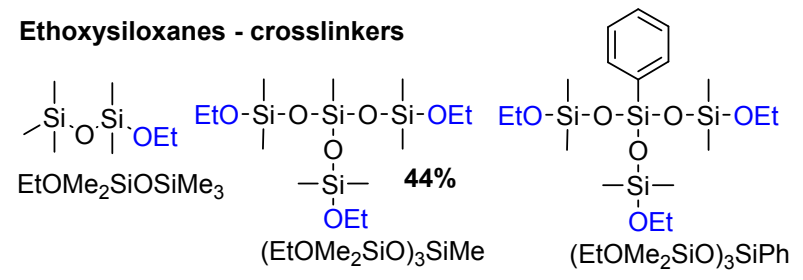
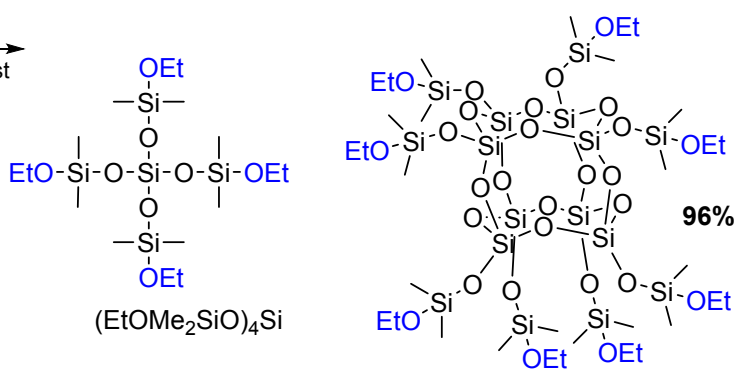

Hydrosiloxanes - polymers

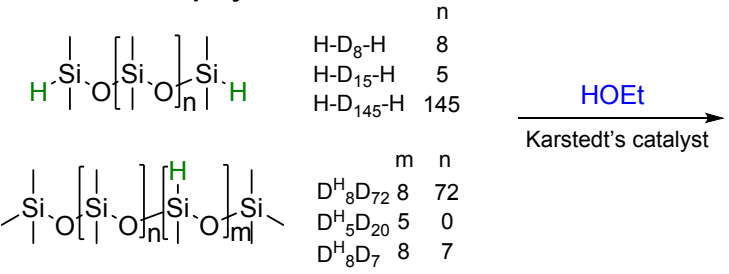

Ethoxysiloxanes - polymers

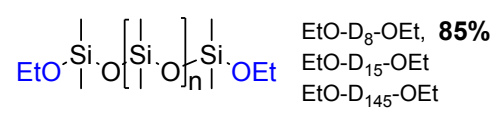

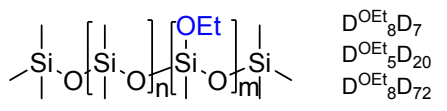

B 

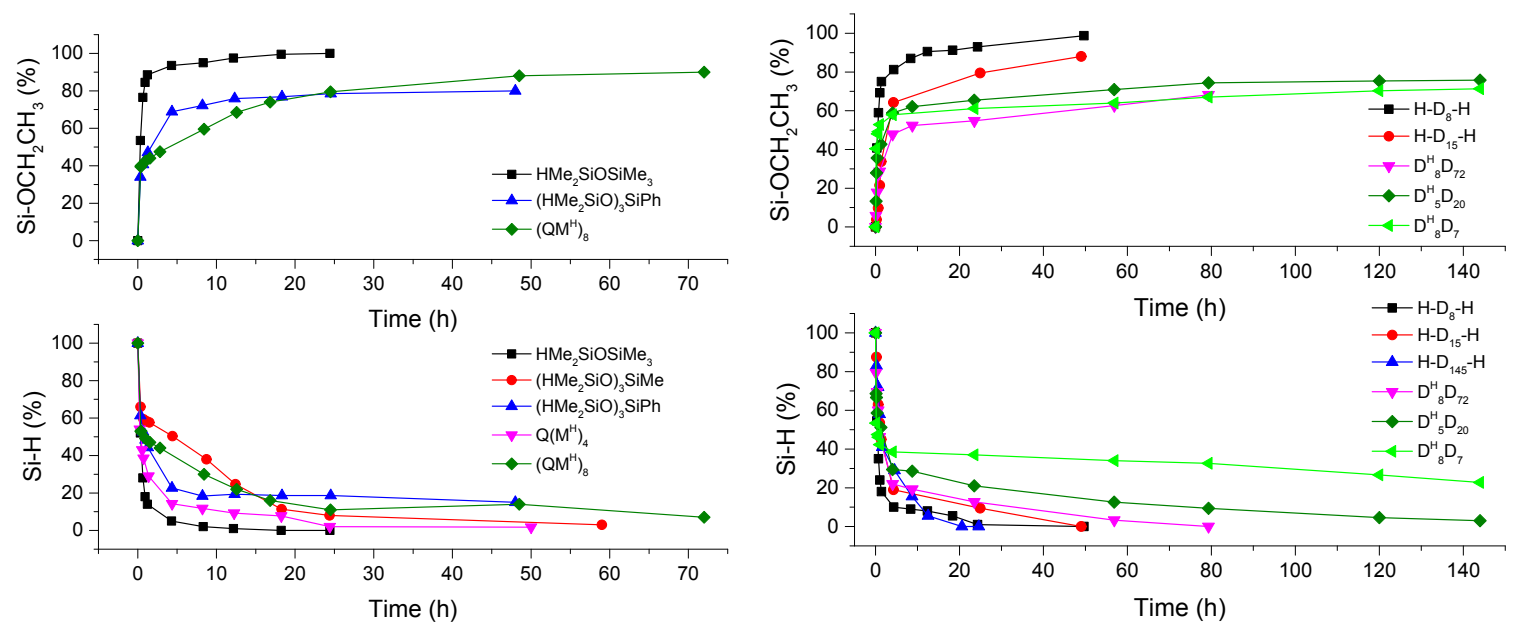

Figure 4. A: Ethanolysis of selected hydroxysiloxanes using Karstedt's catalyst (top). B: Loss of $\mathrm{Si}-\mathrm{H}$ group (\%) and growth of $\mathrm{Si}-\mathrm{OCH}_{2} \mathrm{CH}_{3}$ group (\%) concentration during the ethanolysis using 500 ppm of Karstedt's catalyst.

Hydride-terminated polydimethylsiloxanes $\mathbf{H}-\mathbf{D}_{\mathbf{n}}-\mathbf{H}$ were slowly converted to ethoxyterminated analogues (within 2 days). Pendant methylhydrosiloxane-dimethylsiloxane trimethylsiloxane terminated copolymers $\mathbf{D}^{\mathbf{H}}{ }_{\mathbf{m}} \mathbf{D}_{\mathbf{n}}$ were found to require higher concentrations of the catalyst to reach full conversion of the $\mathrm{Si}-\mathrm{H}$ groups over the same time period. This observation was expected due to higher steric hindrance near the HMeSiO moieties on the polymer backbone. All tested $\mathrm{SiH}$ crosslinkers were fully converted to the ethoxy equivalents except $\left(\mathrm{HMe}_{2} \mathrm{SiO}\right)_{3} \mathrm{SiPh}$ and $\left(\mathrm{QM}^{\mathrm{H}}\right)_{8}$ that required yet higher concentrations of platinum to be used.

\section{Synthesis of alkoxysiloxanes- larger scale reactions}

Selected hydrosiloxanes were converted with ethanol to the corresponding ethoxy analogues in larger scale (Figure 4). The reactions were done at room temperature and led to products without side reactions either from hydrolysis or condensation of the functional groups. Both crosslinkers and linear polymer chains were prepared. The trifunctional crosslinker $\left(\mathrm{EtOMe}_{2} \mathrm{SiO}\right)_{3} \mathrm{SiMe}$ was 
prepared only with a relatively low reaction yield ( $\sim 44 \%)$, which was a consequence of the high volatility of the starting material. By contrast, the higher molecular weight, octa-functional crosslinker $\left(\mathrm{QM}^{\mathrm{OEt}}\right)_{8}$ was synthesized in a high reaction yield of $\sim 96 \%$ and a linear polymer derived from non-volatile starting materials was also prepared in high yield (EtO- $\mathrm{D}_{8}$-OEt, $85 \%$, Figure 4).

\section{Discussion}

The hydrosilylation of alkenes catalyzed by Karstedt's catalyst, commonly used as a silicone elastomer curing technology, is extremely efficient. For most formulations, only a few ppm of platinum are required for efficient processes. However, the alcoholysis of hydrosiloxanes is much less efficient. For practical reactions to occur (within less than a day), approximately $500 \mathrm{ppm} \mathrm{Pt}$ were required (Figure 2). This quantity is similar to that reported for the preparation of tris(alkoxydimethylsilyl)methane derivatives. ${ }^{12}$ In part, this requirement for high Pt loadings may be attributed to the competing reaction of platinum colloid formation from Karstedt's catalyst, which is known to occur in HSi-rich media, particularly when good recipients for hydrosilylation, such as alkenes, are not available. ${ }^{17}, 20$ That is, a fraction of the active platinum catalyst is lost through conversion to much less reactive platinum colloids, which was shown by the production of a yellow to brown color during the reaction. ${ }^{21}$

Alkoxysilanes (silyl ethers) are widely used in the organic community as protecting groups, particularly for alcohols. ${ }^{19,22}$ The relationship between the formation/hydrolytic cleavage reactions of the alkoxysilanes and steric bulk is well known. The rates of both reactions are retarded as the bulk on silicon increases and, to a much lesser extent, to the bulk on carbon. This trend was similarly observed here (Figure 3), where $t$ - $\mathrm{BuOH}$ reacted much more sluggishly than primary alcohols. 
Methanol was an outlier, as it was expected to react most rapidly on steric grounds. The effect may be ascribed to issues of solubility. The work of Lee et al. showed that the solubility of PDMS in alcohols followed the trend: methanol $(\mathrm{S}=1.02)<$ ethyl alcohol $(\mathrm{S}=1.04)<1$-propanol $(1.09)$, where S represents the ratio between the length of PDMS in the solvent over the length of the dry PDMS. ${ }^{23}$ The reaction rates shown in Figure 3 are then influenced by combination of two factors: the solubility of the $\mathrm{H}-\mathrm{D}_{8}-\mathrm{H}$ and Karstedt's catalyst in the alcohols; and, the steric effect of the alcohols. The slower reaction rate of the methanolysis compared to the ethanolysis or butanolysis can be then explained by lower solubility of the $\mathrm{H}-\mathrm{D}_{8}-\mathrm{H}$ and Karstedt's catalyst in methanol.

The group of Marciniec has demonstrated the extremely efficient conversion of a variety of silsesquioxane hydrides into the corresponding alkoxy equivalents (contaminated, in some cases, with very small amounts of disiloxanes), mostly using a palladium catalyst. ${ }^{14}$ However, they showed Karstedt's catalyst, at the higher end of the concentrations examined here, was able to convert a mono $\mathrm{SiH} \rightarrow \mathrm{SiOMe}$ silsesquioxane, and other hydridosilsesquioxanes into phenoxysubstituted silsesquioxanes. Their experience suggests that $\mathrm{Pd} / \mathrm{C}(\mathrm{Pd}$ on activated carbon) is a good alternative for oxidation of hydrosiloxanes.

What is the justification for silicone manufacturers, in particular, to consider using Karstedt's catalyst to create alkoxysiloxanes? There are several advantages. When silicone polymers are exposed to (even low concentrations of) acids or bases, an equilibrium is established between shorter molecular weight silicones and cyclic siloxane monomers. ${ }^{3}$ The main benefit of this method is related to the mild reaction conditions that do not lead to silicone equilibration. In addition, one simple alcoholysis reaction can be used to create both small molecule and polymeric alkoxysiloxanes crosslinkers or chain extenders (Figure 4). Finally, while more catalyst is required for this alcoholysis than hydrosilylation, Pt is widely used in house, and spent catalyst can be 
recovered since the products are readily removed from the catalyst by filtration. Efficient methods for Pt recovery and reuse are already in use; ${ }^{24}$ and the starting $\mathrm{H}-\mathrm{Si}$ compounds are already used in commerce.

Moisture cure RTV is a mild convenient route to well defined silicone elastomers. However, the traditional use of small molecule silane crosslinkers has its disadvantages. The rate of reaction of polyfunctional molecules drops off dramatically in sol-gel curing processes. With tetraethoxysilane (TEOS), for example, the first and second EtO group are rapidly replaced by silanol-terminated polymer nucleophiles. The third and fourth groups react significantly more slowly, frequently as a consequence of steric constraints. ${ }^{25}$ In practice, 'final cure' may take a very long time or, due to low degrees of mobility, be impossible for elastomers based on single point silicon crosslinkers (i.e., $(\mathrm{RO})_{3} \mathrm{SiR}^{\prime}$, or $\left.(\mathrm{RO})_{4} \mathrm{Si}\right)$. Tri- and tetrafunctional crosslinkers prepared using alcoholysis that have much higher degrees of freedom - $\left(\mathrm{Q}\left(\mathrm{M}^{\mathrm{OEt}}\right)_{4},\left(\mathrm{QM} \mathrm{MEt}_{8}\right.\right.$, $\left(\mathrm{EtOMe}_{2} \mathrm{SiO}\right)_{3} \mathrm{SiMe}$ - will be far less susceptible to steric constraints; all the functional groups are located at chain termini (Figure 4), which will allow creation of specific network structures at more convenient rates.

Silicone elastomer properties depend on network structure. One would like to design networks that will readily form without the steric issues noted above and, in addition, go beyond traditional tri- and tetrafunctional crosslinkers. The ability to use the alcoholysis process to create telechelic EtO- $\mathrm{D}_{\mathrm{n}}$-OEt and pendent $\mathrm{D}^{\mathrm{OEt}}{ }_{\mathrm{m}} \mathrm{D}_{\mathrm{n}}$ ethoxysilane-based compounds allows further tailoring of networks formed during RTV processes. That is, it should be possible to prepare designer elastomers that cure in convenient time scales from commercial telechelic silanol polymers and one or more small molecule and polymeric alkoxysiloxanes (Figure 4) to permit control over 
network structures, including $\mathrm{M}_{\mathrm{C}}$ and, therefore, desirable properties including extension at break, modulus, etc. ${ }^{5,26}$

Small molecule and polymeric hydrosiloxanes are commercially available and commonly used for the synthesis of addition curing silicone elastomers. The range of commercially available ROcompounds is rather limited compared to the H-compound analogues. However, H-Si compounds can be easily converted into RTV-active RO-Si compounds using the same platinum catalyst as is used for addition cure. That is, the chain-extending and crosslinking entities used for hydrosilylation may now be accessed as alkoxysiloxane analogues for RTV cure. Although expensive Karstedt's platinum catalyst is required for the alcoholysis reaction, it can readily be recovered from the process. The alcoholysis reaction avoids redistribution processes that can initiate loss of silicone structural features, including molecular weight. This permits complex, active RTV crosslinkers and chain extenders to be prepared in good yield that, in turn, can be used to design complex RTV networks.

\section{Conclusions}

Commercially available small molecule and polymeric hydrosiloxanes, commonly used for preparation of addition curing silicone elastomers, were converted to their alkoxy analogous using mild conditions in the presence of Karstedt's catalyst. Although relatively high amounts of the Karstedt's catalyst are required, the catalyst can be collected and regenerated after the reaction is completed. The alkoxy analogues of the $\mathrm{SiH}$ compounds prepared in this study enrich the possibilities to tailor network structures derived from moisture induced, room temperature vulcanization.

Supporting Information. Stacked NMR plots for kinetics experiments.

\section{Acknowledgments}


We acknowledge the financial support of the Natural Sciences and Engineering Research Council of Canada and an Otto Mønsted Visiting Student award to Alena Jurásková.

\section{References}

1. de Buyl, F., Silicone sealants and structural adhesives. Int. J. Adhesion Adhesives 2001, 21 (5), 411-422, DOI $10.1016 / \mathrm{s} 0143-7496$ (01)00018-5.

2. van Der Weij, F. W., The action of tin compounds in condensation-type RTV silicone rubbers. Makromol. Chem. 1980, 181 (12), 2541-2548, DOI doi:10.1002/macp.1980.021811211. 3. Brook, M. A., Silicones, in Silicon in Organic, Organometallic and Polymer Chemistry, Chap. 9. Wiley: New York, $2000 ;$ pp 256-308. 4. Colas, A.; Curtis, J., B - Silicones. In Biomaterials Science (Third Edition), Ratner, B. D.; Hoffman, A. S.; Schoen, F. J.; Lemons, J. E., Eds. Academic Press: 2013; pp 8291 .

5. Ogliani, E.; Yu, L.; Mazurek, P.; Skov, A. L., Designing reliable silicone elastomers for high-temperature applications. Polym. Degrad. Stabil. 2018, 157, 175-180, DOI $10.1016 / j \cdot$ polymdegradstab.2018.10.012.

6. Zhou, X.; Fan, X.; He, C., Hybrid Starlike Block Copolymer POSS-(PDMAEMA-b-PNIPAm) 8: Thermal Gelation and Its Blends with Poly (vinyl alcohol). Macromolecules 2016, 49 (11), 4236-4244, DOI 10.1021 /acs.macromol.6b00534.

7. Delucia, N. A.; Das, N.; Vannucci, A. K., Mild synthesis of silyl ethers via potassium carbonate catalyzed reactions between alcohols and hydrosilanes. Org. Biomolec. Chem. 2018, 16 (18), 3415-3418, DOI 10.1039/C80B00464A. 8. Lukevics, E.; Dzintara, M., The alcoholysis of hydrosilanes. J. Organomet. Chem. 1985, 295 (3), 265-315, DOI $10.1016 / 0022-328 \times(85) 80314-4$.

9. Corey, J., Dehydrogenative Coupling Reactions of Hydrosilanes. In Advances in Silicon Chemistry, Larson, G. L., Ed. JAi Press Inc.: 1991; Vol. 1, pp 327-387.

10. Clarson, S. J.; Mark, J. E., Siloxane elastomers. In Siloxane polymers, Clarson, S. J.; Semlyen, J. A., Eds. PTR Prentice Hall: Englewood Cliffs, NJ, 1993; pp 616-648. 11. Safa, K. D.; Abbasi, H.; Teimuri-Mofrad, R., Synthesis of novel ferrocenyl silyl ethers via dehydrocoupling reactions under Karstedt catalyst. J. Organomet. Chem. 2013, 740, 56-60, DOI $10.1016 / j \cdot j o r g a n c h e m .2013 .04 .027$. 
12. Safa, K. D.; Sharifi, E.; Tofangdarzadeh, S.; Hassanpour, A., Facile Synthesis of Tris(alkoxydimethylsilyl)methane Derivatives via Alcoholysis Under Open-Flask and Mild Conditions. Phosphorus Sulfur Silicon Relat. Elem. 2010, 185 (12), 2433-2440, DOI 10.1080/10426501003685783.

13. MarcIniec, B.; Gulinski, J.; Urbaniak, W.; Kornetka, Z. W., Comprehensive Handbook on Hydrosilylation Chemistry. Pergamon: Oxford, 1992 .

14. Brzakkalski, D.; Walczak, M.; Duszczak, J.; Dudziec, B.; Marciniec, B., Chlorine-Free Catalytic Formation of Silsesquioxanes with $\mathrm{Si}-\mathrm{OH}$ and Si-OR Functional Groups. Eur. J. Inorg. Chem. 2018, 2018 (45), 4905-4910, DOI $10.1002 /$ ejic.201800582. 15. Jeon, M.; Han, J.; Park, J., Catalytic Synthesis of Silanols from Hydrosilanes and Applications. ACS Catalysis 2012, 2 (8), 1539-1549, DOI 10.1021/Cs300296x.

16. Lickiss, P. D., The Synthesis and Structure of Organosilanols. In Advances in Inorganic Chemistry, Sykes, A. G., Ed. Academic Press: 1995; Vol. 42, pp 147-262.

17. Lewis, L. N.; Lewis, N., Platinum-catalyzed hydrosilylation - colloid formation as the essential step. J. Am. Chem. Soc. 1986, 108, 7228-7231, DOI 10.1021/ja00283a016. 18. Wuts, P. G. M.; Greene, T. W., Greene's Protective Groups in Organic Synthesis. 4th ed.; Wiley: 2007.

19. Kocienski, P., Protecting Groups 3rd ed.; Thieme: Stuttgart, 2005.

20. Crivello, J. V.; Fan, M., Simultaneous hydrosilation and ring-opening polymerization as a route to novel polymer architectures. Macromol. Symp. 1994, 77 (1), 413-421, DOI 10.1002 /masy.19940770143.

21. Stein, J.; Lewis, L. N.; Gao, Y.; Scott, R. A., In Situ Determination of the Active Catalyst in Hydrosilylation Reactions Using Highly Reactive Pt(0) Catalyst Precursors. J. Am. Chem. Soc. 1999, 121 (15), 3693-3703, DOI 10.1021/ja9825377. 22. Wuts, P. G. M.; Greene, T. W., Greene's Protective Groups in Organic Synthesis. 4th ed.; Wiley-Interscience: New Jersey, 2006 .

23. Lee, J. N.; Park, C.; Whitesides, G. M., Solvent Compatibility of Poly(dimethylsiloxane)-Based Microfluidic Devices. Anal. Chem. 2003, 75 (23), 6544-6554, DOI $10.1021 / \operatorname{ac} 0346712$.

24. Yang, G.; Wei, Y.; Huang, Z.; Hu, J.; Liu, G.; Ou, M.; Lin, S.; Tu, Y., Rapid and Efficient Collection of Platinum from Karstedt's Catalyst Solution via Ligands-Exchange-Induced Assembly. ACS Appl. Mater. Interfaces 2018, 10 (7), 6778-6784, DOI $10.1021 /$ acsami.7b19644. 
25. Issa, A. A.; Luyt, A. S., Kinetics of Alkoxysilanes and Organoalkoxysilanes Polymerization/ A Review. Polymers 2019, 11, 537, DOI 10.3390/polym11030537.

26. Mazurek, P.; Vudayagiri, S.; Skov, A. L., How to Tailor Fexible Silicone Elastomers with Mechanical Integrity: a

Tutorial Review. Chem. Soc. Rev. 2019, 48 (6), 1448-1464, DOI 10.1039/C8CS00963E.

ACS Paragon Plus Environment 


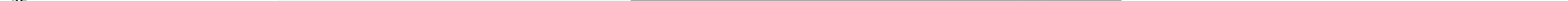

